International Journal of Advanced Studies in Humanities and Social Science (IJASHSS) Available online at http://www.ijashss.com

Volume 8, Issue 1 (2019) pp. 45-60

Original Article

\title{
Defining Elements and Causes of Creating a Sense of Attachment and Belonging to Place by Studying the Interaction between Humans and the Artificial Environment
}

\author{
Amin Bahramian', Siamak Panahi' ${ }^{2}$, Jafar Yousefpour ${ }^{3}$, Farzad Zarbakhsh ${ }^{4}$ \\ ${ }^{1}$ Assistant Professor, Department of Architectural Engineering, University of Isfahan, \\ Isfahan, Iran \\ ${ }^{2}$ Assistant Professor, Department of Architectural Engineering, Islamic Azad University, \\ Abhar Branch, Zanjan, Iran \\ ${ }^{3} \mathrm{PhD}$ in Architectural, Department of Architectural Engineering, University of Isfahan, \\ Isfahan, Iran \\ ${ }^{4} \mathrm{PhD}$ in Architectural, Department of Architectural, Hajat Tape University, Ankara, Turkey
}

Received: 24 October 2018, Revised: 05 December 2018, Accepted: 20 December 2018

\begin{abstract}
Location is not only a shelter for human activities, but also it is a phenomenon that human gives it meaning with his interaction, attached to it, sometimes even he recognizes himself with it. If we look at it as a need of human being viewpoint, man need to emotional interaction with the place he lives or in other word belonging to place is the most important aspects of interaction of human being with place that should be care by urban planners, designer and architecture. So this study base on literature review and related data in this field and with defining belonging to place, reviewing different dimension of it and categorizing of reasons attempt to describe new model of elements and forming process about human and place interaction. Results indicate that the attachment to sites has different dimensions of emotional, cognitive, and behavioral performance. In addition, the quality of interaction are formed based on five key elements, including humans, location, participation in the location planning, location and time factor in how human interaction.
\end{abstract}

Keywords: Artificial Environment, Place Attachment, Place Identity, Emotional Interaction, Functional Dependence.

\section{Introduction}

Before $70 \mathrm{AD}$ in studies of the relationship between people and place, attachment to place, had not been considered. In the past 25 years, factors such as personal space, realm, density, sense of place and related matters to the subject of the research on people and place were the research issues.
But increasing rapidly increasing impact of culture on preferences regarding location, population movement in the cities and the need to comply with the new environment, interest in the growing community of sites, such as design for the elderly, children, homeless people and different social 
groups, cause that human emotion toward location become one of axis of the most investigation. Currently, many studies have been conducted and several measures of place attachment in the home, neighborhood, town and country and different places, including workplaces, educational facilities, public and recreational spaces have been studied in this regard. In addition, experts from different fields of design, psychology, environmental psychology, sociology and anthropology related to environmental and human dimensions of several researches and studies have shown this emotional connection.

\section{Methodology}

This methodology is based on data study and literature review related to significant and prominent research in place attachment field. This article is based on three parts: the first part, theories and definitions have been raised about this case study. The next steps the results of study have been done and all reasons in this field will be categorized. In the last step the attempt is based on results of previous stages, consisting of a model of attachment to place, and the process of its formation, is introduced.

\section{Attachment Theory}

Studies on the attachment for the first time has been researched in the relationship between health care staff and children and how children in the treatment process, develop their confidence in the medical team (Marris, 1996; Goldberg, 2000) In general, the attachment to topic such as object, place, person and other issues faced by people in their everyday life, and based on previous experiences of life, structures, behavioral, cognitive, emotional and social "self" and all new experiences may resort and coping with new subject on the basis of perceived plan, organize, and sort. In addition, the plan itself is the driving motivation of individual behavior. At the same time, so that the "self" is made the needs and expectations of the person and the object or subject that can meet these needs is also made, person feel a sense of comfort and security and, on the basis of objective and subjective needs come to real world. Therefore, it is an object or subject is absorbed and expressed their emotions on the basis of this appeal, he care and attention to this appeal (Figure 1).

Resulting in the attachment, will keep desire to live with others, stable and purposeful behavior (Marris, 1996 in Hashas, 2003). When a threaten is cause of lost a kind of emotional attachment and reaction - meaning is created that its result is grief (Marris, 1996 in Hashas, 2003) attachment to the object that is causing a lot of research on the basis of their attachment to place. The reflection indices with complex meanings and definitions frequently used in environmental studies and has particular importance.

\section{Defined and Indicate Attachment to Place}

The term attachment refers to emotional location, that people are attracted to it emotionally and culturally. Effect of sensory, emotional and inner space of the human attachment to place is the center of thought, because humans can absorb by an object, house, building, neighborhood, or a natural place (Low and Altman, 1992). Attachment to a place where the whole 
sense of positive emotional attachment that develops between people and place (Stedman, 2003). These words show one's feelings towards a geographic location that bond individual to it (Milligan, 1998). In fact the positive experience group or an individual in connection with a place to make good sense (Rubenstein \& Parmelee, 1992) and in this process, they develop their relationships with others and where they live.

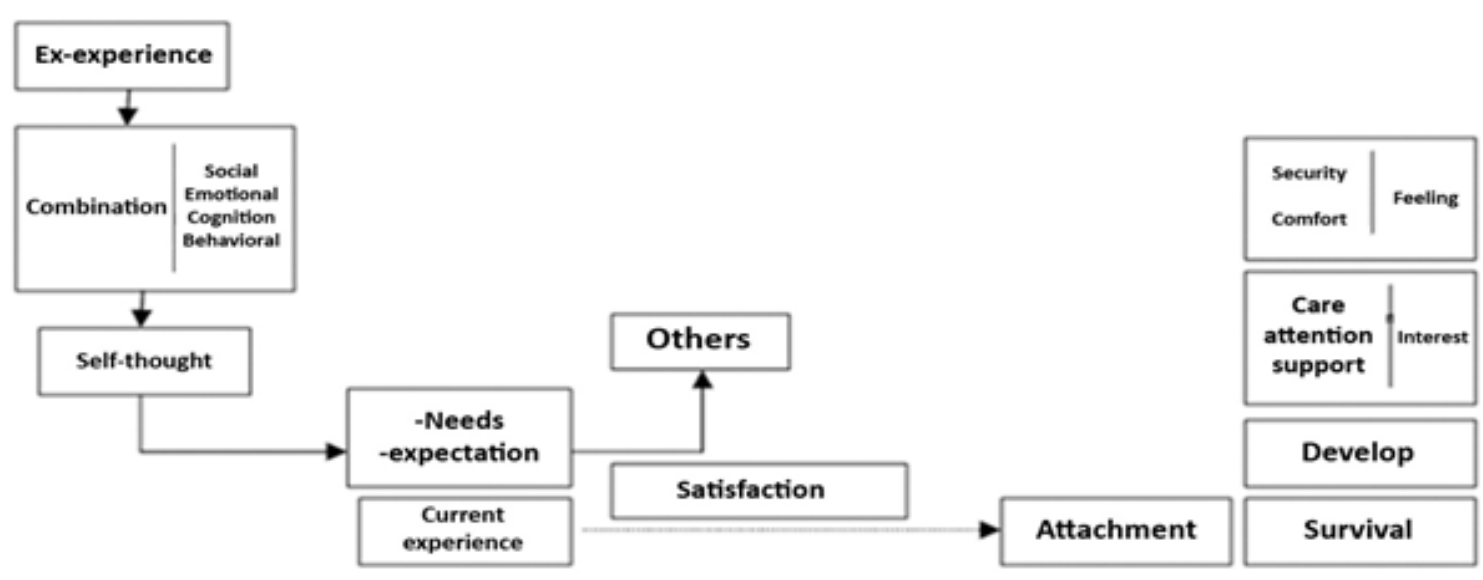

Figure 1. Attachment theory. Source: (Hashas, 2003)

Attachment to place arising from the interaction between human activity and attachment sites - places and people - in one particular place (Relph, 1976; Low \& Altman, 1992). And in the interaction with feelings, knowledge, beliefs and behaviors, deal with a specific location (Proshandky et al. 1983, 155) as Ahranzan, knows it in places associations between individual, social knowledge and beliefs (Ahrentzen, 1992). In addition, in the attachment between the person and the place where his focus there is a direct relation, in the sense that increasing an individual 's attachment to a place, cause to increases the level of individual care and attention (Mesch and Manor, 1998).

On the other hand however attachment arising from individual emotional interaction with place and is based on self and inner reaction but it up to social attachment too. (Kyle et al., 2004). As far as the term use in form of such words like community attachment and sense of community, and sense of place.
Schumacher and colleagues also states positive emotional attachment between people and place that these words suggests that social groups, physical desirability, personality and status received from the location of the roles (Shumaker and Toylor, 1983). Attachment to place, due to the interest, knowledge and experience in relation to location is built on personal characteristics and social relations between different cultural groups (Low and Altman, 1992). In fact, it is based on the interaction of cognitive, emotional and behavior between individuals, groups and physical space - social, consciously and unconsciously is formed over time, (Brown and Perkins, 1992) and the emotional connection between individual and place is established, on the basis of judgments, preferences and knowledge of the location. (Riley, 1992). Bonaito et al. states attachment to place as a part of place identity and claim that in this frame social and psychological process will appear and its result is feeling and interest to place. (Bonaiuto et al., 1999). Jacobs refers that 47 | Page 
attachment is a deep human feature and some people in face with some places say that I belong to it and gives the home conception to it (Jacobs, 1995).

\section{Forms and Dimensions of Attachment to Place}

As stated in the definition, attachment refers to the relationship between sensory and emotional attachment to the place. This means that people explore places that are attached to it and why it has been referred to in various dimensions. Many researches attempt to evaluate this concept. Studies shows that attachment has various dimensions it means that people has effective role in place indication and its dimension.

For example, Taylor attachment to place on these dimensions defines:

Physical dependence: having root point that refer to the old location and time which is familiar with it.

Social dependence: constraints and local provisions or the social ties of individuals and groups in space (Taylor et al., 1985).

Lowe's and Altman are the most important theorists in the field of attachment to describe the location based on the following dimensions:

1 - Specific areas: the importance of social meaning in terms of location, however, creates an emotional attachment to it (Tuan, 1977).

2 - Location identity

3 - Inside location (Relph, 1976)

4 - Location kind

5 - Rooted in place,

6 - Environmental Visualization

7 - The feeling of mass

8 - Identify the name (Low and Altman, 1992)

In general, the determination of the dominant there are two main perspectives on attachment to place:

\section{First Perspective}

As noted in attachment theory when we attach to an object that form it will be evaluated in one hand response to expectation and on the other hand is made by mental visualization by self. Based on this theory, the first view includes both functional and emotional attachment to the place is as follows:

\section{Functional Dimension}

This dimension refers to meet the needs and people's goal (Williams and Roggenbuck, 1989; Schreyern, et al.). It is based on place quality in response to user's needs in comparison to other places. That is up to ex-experience of individual (Warzech and Lime, 2001) kind of availability to place and activities patterns (Vaske and Korbin 2001).

\section{Emotional Dimension}

The dimensions relate to location of sensory interaction and its role in personal identity (Williams and Roggenbuck, 1989; Schreyer et al., 1981). And the dimensions of the "self" refers to the expression of one's identity in relation to the physical location (Proshansky, 1978), this type of motivation was the attraction sites and spending time (Scherl, 1989), it bonds to sense of individual toward a specific location (e.g., certain elements in place or its history) (Warzecha and Lime, 2001). And over time and with repeated visits to they are formed. This also created the sense and meaning of individual lives (Tuan, 1977), resulting in a responsive and responsible behavior towards the development site also improve environmental behavior (Vaske and korbin, 2001).

This dimension has been investigated as social belonging, which is based on sense of place and experiences and shared memories with others (Hidalgo and 
Hernandez, 2001; Liw and Altman, 1992; Kyle et al., 2004; Willams et al., 1992).

\section{Second View}

In this view, attachment to place, depending on the location and identity of the two-dimensional space is defined (Williams et al., 1992; Bricker and Kerstetter, 2001).

\section{Location Dependency}

Dependence space is defined by following three Dimensions:

A: The ability to respond to the needs of individual sites or in other words the opportunities He provides a place to meet the needs and goals (Stokols and Shumaker, 1981). It implies the presence or participation in certain activities on the Site (Bricker and Kerstetter, 2001; Hammitt et al., 2004).

(B) In relation to the emotional impact of space: positive or negative feelings towards a place (Rosenburg and Havland, 1960)

D: The amount of location -based prior experience;

Number of previous experience of similar places;

Frequency of attendance at a particular location;

The location of the stop.

In fact attachment to place is a part of functional attachment to place that reflect kind of individual relationship with place and cause to make continuous relationship between individual and specific place that base on it have the ability to response individual goal and activities (Williams and Vaske, 2003).

This assessment is then described with these words:

- The best place to do activities that they enjoy;

- Work that I do is more important than any other activity;
- do not replace another place for those activities;

- I am satisfied to see here than other places;

- I feel better in the same place.

It also depends on the demographic characteristics, the motivations, the method of perception, evaluation, management, location and type of activity is in place (Harmon, 2006).

\section{Place Identity}

A person who designs the first paper, "The city and its identity," was Prashansky who search the question of identity. His interpretation of this phrase is evaluated to identify the location of this place that I am. He explained dimensional space identity of "their" personal identity in relation to place (physical) based on the beliefs, preferences, feelings, values, goals, desires, behaviors and skills in relation to the location of the conscious and unconscious. But it depends on the individual's identity, location, specific experiences and how her socialization reflects those individuals and groups who live in a particular place (Proshansky, 1978). Ralph Lynch on studies, defined the identity of place, "a place of identity, dignity or which creates spatial differentiation as a whole is distinguished by its knowledge base." Make a specific location or place files for them. Location, identity, image production, experiences, thoughts, memories, emotions are immediate and meaningful interpretation of what it is and what it should be (Relph, 1976). This ties to a place with anatomical structures and distinguish it from other places. However, the identity, location, location -based symbolic importance of an emotional attachment with the place, emotions and relationships as well as within the individual's life purpose and gives meaning (Williams and Vaske, 2003) 
in relation to the location or the unique spirit of place, the identity of which can be built with the changes in the elements, and have sustained various levels as follows:

Individual level: varies between different people:

A social level: the symbol of signs, common meanings and social interactions within groups and communities;

General level: The general agreement and the imagination of the masses by the media, government and other institutions, dictated a level and is based on shared meanings and symbols.

Center of this quality factor of the location is called by Prashanky person past place history. Furthermore, the type and characteristics of the site are as a tool to meet their cultural needs - social, psychological and physiological individual, contribute (Prohansky et al., 1983). The dimensions of place identity are classified into three dimensions:

1 - The cross - Cognitive: these is related to impressions, memories, conscious and unconscious thoughts and beliefs about the characteristics of the physical location of a person.

2 - The evaluation - Emotional dimension: This is the type of person rather than a sense of location content such as color, style, form, sound, dimensions, lighting and other factors, the loss of the relationship.

Another aspect of this dimensions is, how to combine elements of the real world in a place where individuals and groups can experience. The dimensions of each person are unique, but some groups also have this in common. The next is such words like: room, my favorite, my city and expressions of this expression is then evaluated the expression of consciously or unconsciously - a place of emotional identity.
3 - Base topic and an individual needs toward place: This dimension indicate with one's role and set of expectations, beliefs, feelings, ideas, infusion due to its location in relation to the expectations and needs of place and person) Prashansky perspective usually when they are consistent is understandable (ibid) he does not pay attention to, the cultural context and social that influence the formation and development of place identity. In this view, not only stimulating to answer people's reaction to it, but also the context for making sense of the behavior and desires, beliefs, values, and expectations and express one's identity contribute unconscious in describing is relevant (proshansky, 1978).

Level 1: level is a cognition that is a tool for judging and evaluating of place and it will develop stability in time and space for individual.

Level 2: it is a meaning level that person gives meaning to the place and in this stage person will affected by place features that is effective in his role and behavior.

Level 3: analysis is based on an individual's identity and sense of selfworth based on the appraisal of her because the person identity is linked to location identity. Thus, it will create inadequate space, lack of emotion in person (Proshansky, 1983).

Aspects of "self" in relation to personal identity, which can explain the physical location (Proshansky, 1978; Proshansky et al., 1983), reflecting memories stored and abstract representations of self and place in a person (Warzecha and Lime, 2001; Williams et al., 1992; kyle et al., 2003; Vaske and Korbin, 2001; Moore and Graefe, 1994). So, the location identification, based on symbolic elements (e.g., name, location), the kinds of experiences gained in place, sensory and psychological outcomes in relation to one 
place (Giuliani and Feldman, 1993). memories, past, place, people, local scale, quality, location and specific experiences that (Relph, 1976) is formed as individuals based on their specific type of habitat they know and identify with that feeling (Feldman, 1990).

Being motivated is related with a sense of place in one of several factors such as the ongoing experience of place (Moore and Graefe, 1994; Bricker and Kerstetter). The presence of repeated interaction is concerned with the place where the feeling of dependency performance (Moore and Graefe, 1994; Relph, 1976; Williams and Vaske, 2003), rather than its location and feel of meditation and attention (Kyle et al., 2003). The social factors and the amount of people in the place is one of the factors in identity formation of location (Vaske and Korbin, 2001), in other words, people develop this feel by increasing the sense of social dependence (Williams and Roggenbuck, 1989; Moore and Graefe, 1994).

This dimension is described in these words:

- This place is a reflection of my personality

- Looking at it tells me that who I am;

- This place has a lot of meaning for me;

- I feel I can really be myself in this place (Kyle et al., 2004).

\section{Effective Factors in the Formation of Place Attachment}

Studies on attachment to place, pointed out several factors which suggest that in this relationship may be mentioned the role of cultural, social and personal (Low and Altman 1992; Low, 1992 Oswal and Wahl, 2001), physical factors (Marcus and Sarkissian, 1986; Brwer, 1985; Green, 1999), social factors (Cohen and Shinar, 1985; Fried, 1963). With review of literature we can point to effective factors in creating dependency feeling to place that they are described in the following section:

\section{Physical Factors}

Many studies have been conducted in the area of attachment to the body's role in this area (Fried and Gleicher, 1961; Eisenhauer et al., 2000; Stedman, 2003; Handal et al., 1981). This category of studies tries to answer to this question that which place is important to people what is the reason of it? The results indicate that the characteristics of both physical and social place create one of the attachment sites). Stadman studies have been done around physical dimension of place that refer to direct role in satisfaction and indirect role of it in dependency to place while they are affected by symbolic meaning of place (Stedman, 2003). In urban areas, many details about how to communicate with others, including cases that have been referred to in studies (Banaiuto et al., 2002; Lansing et al., 1970).

\section{Social Factors}

Generally speaking environmental psychology not only deal with place dimension but also it deal with social dimension (Bonnes and Secchiaroli, 1995) there is a positive relationship between person, place and satisfaction feeling and social relationship (Chavis and Pretty, 1999). In this respect, two important factors are involved the identity of the location-dependent ecosystems, sharing memories and have the time and interest to it. The physical qualities are only one dimension of space experience (Chawla 1992). And the importance of social relationships that occur in places should not be neglected. As some researchers, public participation in place-based place attachment, social networks and cultural 
interaction employment, which is considered to have an equal role or even more important than the anatomical location (Marcus, 1992).

Attachment has direct relationship with positive interaction growth and social adoption in places (Mesch and Manor, 1998). Accordingly, attachment to place is explained by three factors:

- Characteristics of individual and group user and locations;

- The amount of contact and intimacy of the place;

- Participation in group activities and social events (Brown and Werner, 1985)

Generally, people's attachment to place create on the basis of public interest (Marris, 1996). So how attendance at a place with others, it is to remain a strong factor in the decision. In this way, even those in search of places where people with similar characteristics in terms of class, ethnicity, religion, economic groups, life style, education, income, education of children of the same race are present their requirements. Open to experience (Marcus and Sarkissian, 1986). The important point is receiving suitable social space cause to increase satisfaction and encourage informal interaction and participate in social activities and as a result cause to improve dependency to place (Fisher, 1977; Cohen and Shinar, 1985; Rohe and Stegman, 1994). The positive sense of social communication has been created the world for individuals who are forsaking, and it encourages his patients (Fried, 1963). Since in many cases the desired level of attachment to place are explained by an unfavorable physical conditions and social factors (Bonaiuto et al., 2002).

\section{Cultural Factors}

Groups, families, community members and cultures share the same attachment to a particular place (Hummon, 1992; Low,
1992; Lawrence, 1992). On the other hand, attachments to place, depending on the activities that people do in their cultural requirements (Low and Altman, 1992). So culture may be effective in group interaction (Newell, 1997). Law states that dependency to place is formed in cultural process and he defines 6 cultural tool in this field:

Dynasty: the individual's place within its historical identity is linked with his family;

Loss: make and amplifier attachment to place; Ownership;

Look into cosmology and philosophy of existence: the mythology of a culture and religious views on the individual and his attachment to place is effective;

Pilgrimages and rituals: they are concerned with places that have certain meanings for individuals and groups, such as religious sites;

Narrative: it is about the descriptions and narratives about a certain place in life.

\section{Individual Factors}

The amount of attachment varies from one person to the other person (Tuan, 1997; Riley, 1992). Based on the preferences of the people conscious of their individual characteristics of the place choose and are attached to it. Individuality in social orientation and how to develop intimate social relationships may also be important (Low and McDonogh, 2001) that is called the initial orientation of the mental characteristics (Lansing, 1970). The Davy says, "reflects the identities, locations, and competition between different groups based on gender, class, religion, ethnicity, culture, religion and political orientation represents the people, power, freedom, interests, system interests are in social and consumer incentives »(Dovey, 1999).

In defining characteristics and its role in interactions with various factors noted to some features such as location, age, 
gender, income, marital status, education, social class and occupation (Pretty et al., 2003; Bonaiuto et al., 1999; Cohen and Shinar, 1985), in this regard, even a diet, smoking, exercise and physical activity is also effective (Ellaway and Macintyre, 1997). These factors could be added to their mental and physical abilities (Halpern, 1995). But the characteristics of this dimension is not only limited, but also individual differences, needs, working life, the definition of life (Rubinstein and Parmelee, 1992) mode of thought, perception, imagination and personal purposes in connection with the Site (Gifford, 2002), background, beliefs and personal values are involved in this field (Brower, 1988). In addition these factors to developing social ties, involves a profound sense of place for each person (Low and Altman, 1992). In other words, life experiences for each person has a special sensory qualities, he experiences a sense of attachment to places where it occurred. (Rubinstein and Parmelee, 1992).

Kind of thought, conception, imagination and individual goals in relation to place (Gifford, 2002), background, values has important role in this context (Brower, 1988). They involve deep meaning of place for everyone (Low and Altman, 1992). In other word individual experiences has special feeling quality and create a kind of dependency to place (Rubinstein and Parmelee, 1992).

Some studies suggest that gender is not a determining factor in the attachment to place (Cohen and Shinar, 1985). In the case that more interest in women has been reported due to spending more time with the site. (Marcus and Sarkisssian, 1986). For example, individuals with lower incomes are more likely to have a local social network in their residence. In addition, the formation of social networks in place that is effective in attachment to place, depending on their social and economic conditions, age, duration of residence and field (Oswald and Wahl, 2001; Fried, 1963; Cohen and Shinar, 1985, 1999). In addition, people have better relationship with his birth place and they feel more comfortable (Sanoff, 1970; Rohe and Stegman, 1994; Bonaiuto et al., 1999).

\section{Memories and Experiences}

Dependency to place occur during the long time and in this situation the place has meaning (Prentice \& Miller, 1992; Tuan, 1974; Korpela and Harting Gifford, 2002; Kaplan, 1982). In this regard Tuan pointed to root factor in place that means being merge to place (Tuan, 1980). The Rileyly amidst the students, remind adults of their childhood places and old memories of their location (Riley, 1992). According to him, people form their dependency base on their social relationships, their experiences and their surrounding areas, so that their sense of identity in accordance with the wishes. The settlement reflects the feelings of their choice and recalls the memories of places and people. Because of this feelings that occur within the site and in establishing a sense of place, such a relationship, each person has a distinctive style. In relation to the person - the place is a process of interaction between cause and effect (Marcus, 1992). Chawla in his study refers to children in their studies when evaluating the location; do not refer to the body and physical needs but qualities such as good mental image of the place (Chawla, 1992). Rabynshtayn and his colleagues have done study on attachment of older people and how pleasant or unpleasant experiences are reflected in its current location on living conditions. (ibid, 142), as for older people attachment to place 
means to preserve the past for the old place attachment and personal identity in the face of change. Notably, the interactive individual location, to the extent that it is meaningful depends on experience. What is more important experience or how to get it would be a stronger attachment to the place. The interaction of each person to discover his memories and past experiences and future expectations in certain places, which lies in a stronger attachment to the place it was discovered to be effective. It is also important to note that the location of various ethnic character and activity, the creation of various potential interactions with that person (Milligan, 1998).

\section{Satisfaction Location}

Bond between person and place to place, and manner of evaluation depends on the consent of it (Bonnes and Secchiaroli, 1995). And its value depends on the individual's perception of place and her satisfaction with the quality of security and location (including economic security, social and physical) is that they are receiving consciously or unconsciously, objective or subjective, and individually or collectively, and consequently Security in place for meditation, develop and retain it (Mesch and Manor, 1998). Base on attachment theory, this would not necessarily indicate that it probably occurs when the needs and expectations of people in place to meet. Therefore, one of the most important aspects in this regard should be examined, is their satisfaction with the place. In place to meet the needs and expectations of the likelihood of developing it increases with better emotional relationship (Fisher et al., 1977). Quotes (Cohen and Shiner, 1985) in fact the satisfaction of the location is not isolated from attachment (Keller, 1968 Cohen and Shinar, 1985; Lansing et al,
1970). Satisfaction to location depends on factors such as facilities to the satisfaction of the appropriateness of the location and function, sustainability, visual characteristics, management, economic value, location, embodiment and social context where people of similar units (Marcus, 1992). Architectural features of the city, up to social communication and location background characteristics (Boaiuto et al., 1999).

\section{Engagement and Interaction Factors}

One of the most important of place characteristic that can be improved attachment to the place, is the interactions between human activities - places and people - people at that place (Relph, 1976; Rubinstein and Parmelee, 1992; Low and Altman, 1992). In fact rooted in how people interact with physical space and social interaction, cognitive, behavioral, emotional, and means that the result of attachment to place (Brown and Perkins, 1992; Oswald and Wahl, 2001; Proshansky in Rivilin, 1987; Green, 1999; Rivlin, 1987), thus causing the business activities of place and sense of place is the business sense of their underlying attachment to the place (Relph, 1976; Low and Altman, 1992; Fried, 1963; Brown, 1988 Proshansky, Rivlin, 1987), for example,show in their studies that attachment to place in urban areas, is despite of the happenings and events on a periodic or ongoing activities and to strengthen governing the location. (Relph, 1976 Proshansky in Rivlin, 1987; Low and Altman, 1992; Mazumdar, 1993; Bonaiuto, 1999).

As the cross-cultural studies, have been assessed organizing festivals, celebrations and sports activities organized in urban public spaces, more than anything else in the space draw from different cultures, for effectiveness (Gobster and Delgado, 1993 
Loukaitou- Sideris, 1998). It is noteworthy that there is reciprocal relation between activity and attachment to place (Low and Altman, 1992).

\section{Operating Time}

As we stated before; time of residential to place is one of the key factor to place dependency that most of the researcher confirm this statement (Bonaiuto et al., 1999; Lansing et al., 1970; Rohe and Stegman, 1994).

Time is the essential factor for children and adult dependency (Cohen and Shiar 1985). That is investigated in both process and amount of attachment to place (Rohe and Stegman, 1994, 1988; Appleyard, 1976; Relph, 1976).

\section{Participation in the Design Space}

Participating people in the process of creating places cause them to feel better and better place to have. The development following social communication and attachment to place, maintain historical roots, the place has a sense of peace and security (Rivilin, 1987). At the same time enable participation that reflects the needs and expectations of people towards the place, is crucial to the future of life (Altman, 1993).

\section{Conclusion}

As definitions of attachment to the place shows this term refers to the emotional relationship of person to place. That is rooted in features and pervious experiences of person in one side and ability to response to expectations on the other side. Thus, each of which is able to meet the needs and expectations of the man and his attachment to that location will increases. Responsive and responsible behavior in space will lead to many responsive behaviors toward place. The different effects of attachment to places are drawn together in the following figure (Figure 2).

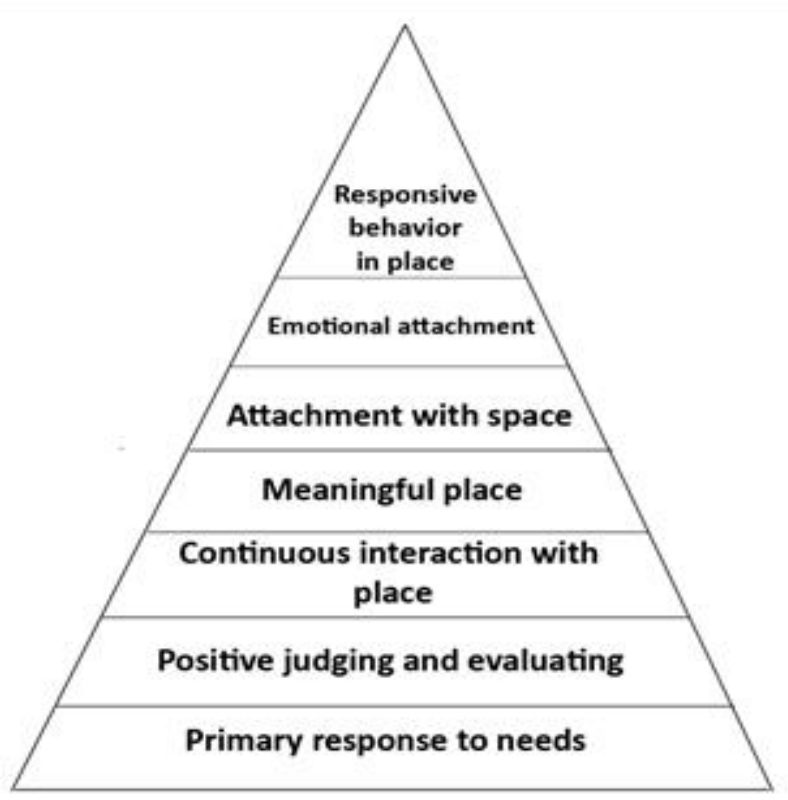

Figure 2. The hierarchy of attachment forms to place based on different aspects (Source: authors)

In the following we look to effective reasons of attachment we can mention two important factors human, place and their features. Prashnscky noted to these points that is self which unwittingly involved and consists of the following three areas: 
Thought and imagination of individual toward place base on previous experience that forms individual judgment. Preferences and feelings towards the place of emotional interaction with the site, how to evaluate the space he creates. Places that meet the needs and expectations of individual responsibility, the functional dependence of the shape space.
In fact base on results in attachment forming processing two elements human and place are involved and third element which is human interaction come to this circle. We can mention two other factors one of them is time and the other is cooperation of designer in this process for improving place dependency (Figure 3).

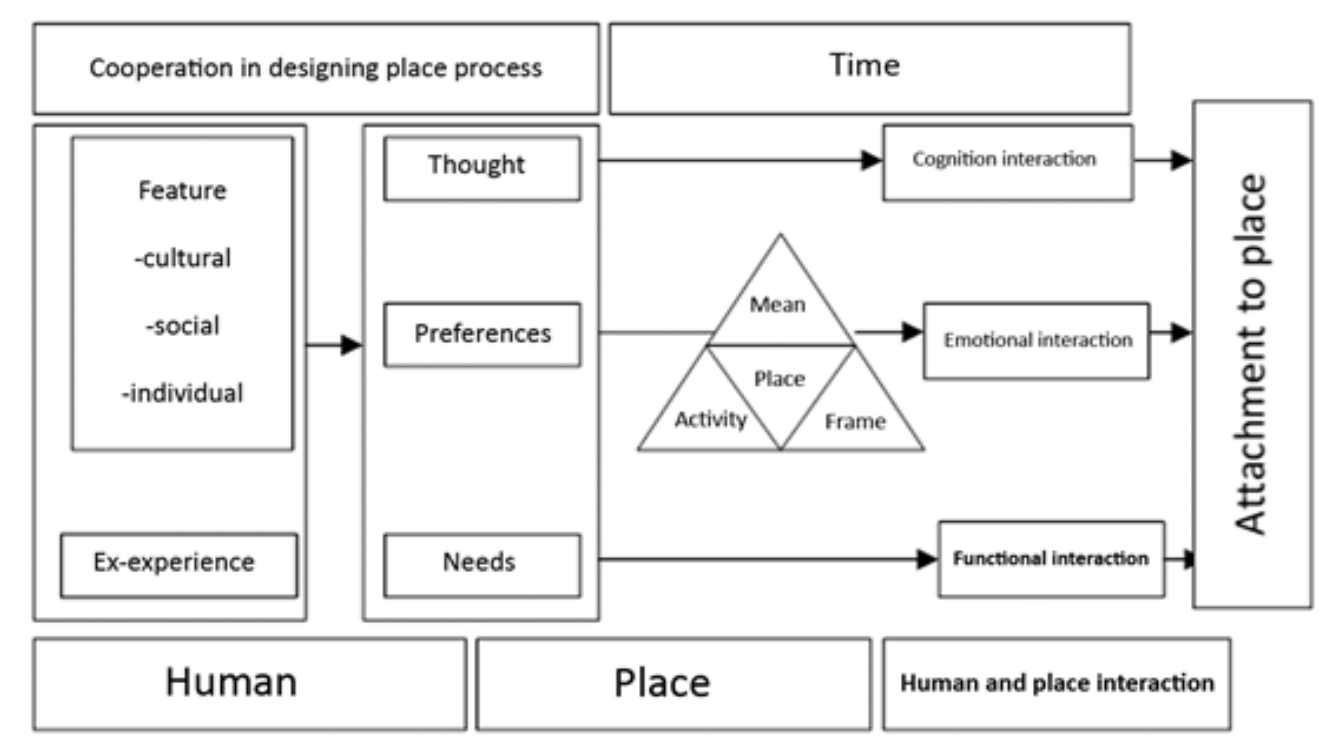

Figure 3. Explained model of attachment process to place (Source: authors)

\section{Man}

With all the features of individual, social, cultural, psychological and physiological key that must be examined in the study of place attachment.

\section{Location}

Should be study with all the physical characteristics, activity and meaning (Canter, 1977). Having different capacities, to meet the satisfaction of individuals and different groups have different emotional impact it has on them. So they can meet, creating beautiful and memorable experiences and the emotional attachment that is causing the above three aspects that should be considered.

\section{Human and Place Interaction}

Human face to place judge base on various feeling and it has been investigated in the form of emotional and functional frame.

\section{Time}

Duration of familiarity of people to place amount of resident duration and neighborhood with that that it is factor which cause attachment.

\section{Cooperation Factor}

It reflects needs and expectation of place user and cause power and ownership and has direct relationship to improve 
dependency. So cooperation should be considered by designers.

It was further noted in the interaction of cognitive, emotional and functional, must be considered. In fact the key elements cause to create index to evaluate attachment.

Figure 4- Defining model from place attachment.

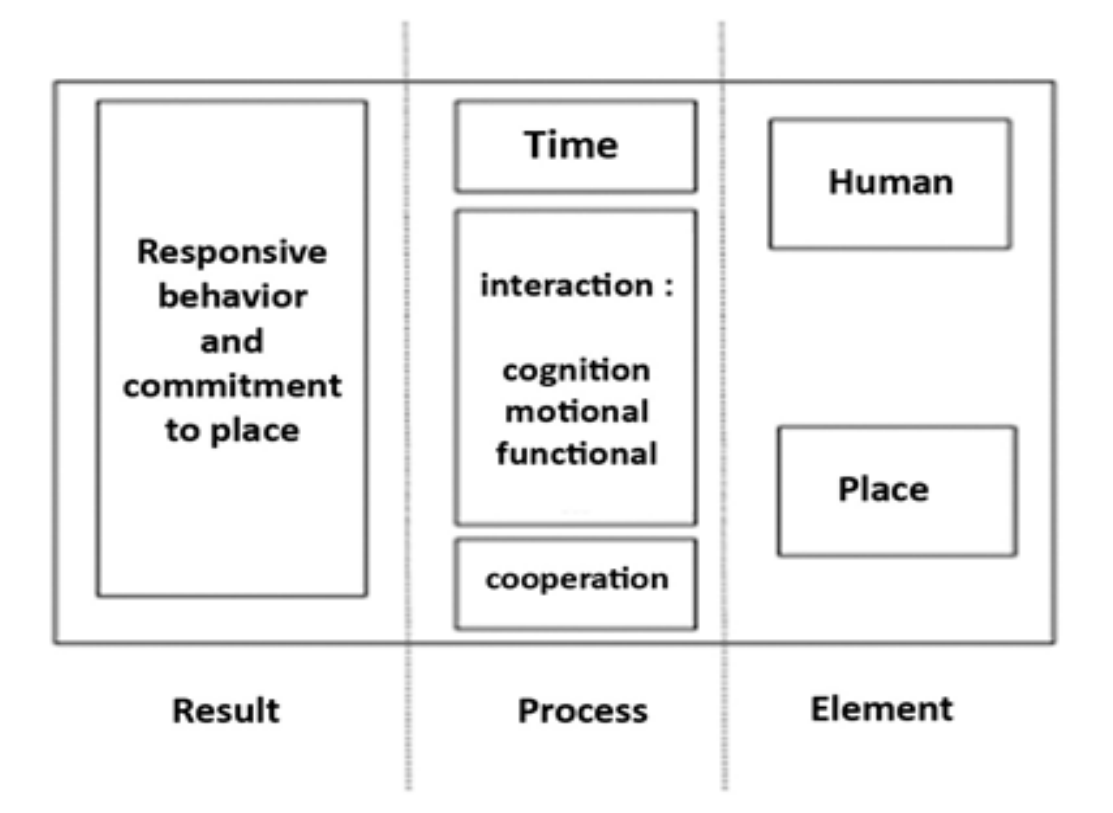

Figure 4. Model explains the process of attachment to place (Source: authors)

\section{References}

Ahrentzen, Sherry. B. (1992). 'Home as a workplace in the lives of women', In I. Altman and S.M. Low, Eds. Place Attachment, New York, Plenum, 113-138.

Altman, I. (1993). 'Dialectics, physical environments, and personal relationships', Communication Monograhphs, 60, 26-34.

Appleyard, D. (1976). Livable urban streets: Managing auto traffic in neighbourhoods, Washington DC, Government Printing Office.

Bonaiuto, M., Aiello, A., Perungini, M., Bones, M. and Ercolant, A.P. (1999). 'Multidimensional Environment quality and neighbourhood attachment', Urban Environment, 19, 331-352.
Bonaiuto, M., Fornara, F., and Bonnes, M. (2002), 'Indexes of perceived residential environment quality and neighborhood attachment in urban environments: a confirmation study on the city of Rome', Landscape and Urban Planning, 988, 1-12.

Bonnes, M. and Secchiaroli, G. (1995). Environmental Psychology Introduction, London, Sage.

Bricker, K.S., and Kerstetter, D.L. (2000). 'Level of specialization and place attachment: An exploratory study of whitewater recreationists', Leisure Sciences, 22, 233-257.

Browser, S. (1988). Design in Familiar Places: What Makes Home Environments Looks Good, Praeger, New York. 
Brown, B.B. and Perkins, D.D. (1992). 'Disruptions in Place Attachment', In I. Atman and S. Low (Eds), Place Attachment, New York, Plenum.

Brown, B.B. and Werner, C.M. (1985), 'Social cohesiveness, territoriality and holiday decorations', Environment and Behaviour, 27, 539-565.

Canter, D. (1977). The Psychology of Place, London, The Architectural Press Ltd.

Chavis, D.M. and Pretty, G. (1999). 'Sense of community: Advances in measurement and application', Journal of Community Psychology, 27:6, 635-642.

Chawla, L. (1992). 'Childhood place attachments', In I, Altman and S. Low (Eds.), Place Attachment, New York, Plenum Press, 53-86.

Cohen, Y.S. and Shinar, A. (1985). Neighbourhoods and Friendship Networks, The University of Chicago, Chicago.

Dovey, K., (1999). Framing Places: Mediating Power in built form, London, Routledge.

Eisenhauer, B.W., Krannich, R.S. and Blahna, D.J. (2000). 'Attachments to special places on public lands: An analysis of activities, reason for attachments, and community connections', Society and Natural Resources, 13, 421-441.

Ellaway, A., and Macintyre, S. (1996). 'Does where you live predict health related behaviors?: A case study in Glasgow', Health Bulletin, 54, 443-446.

Feldman, R.M. (1990). 'Settlement identity: Psychological bonds with home places in a mobile society', Environment and Behavior, 22, 83-229.
Fried, M. (1963). 'Grieving for a lost home', In L.J. Duhl (Ed.), The Urban Condition: People and Policy in the Metropolis, New York, Simon and Schuster.

Gifford, R. (2002). Environmental Psychology: Principles and Practice, Canada, Optimal Books.

Giuliani, M.V. and Feldman, R. (1993). 'Place attachment in a developmental and cultural context', Journal of Environmental Psychology, 13, 267-274.

Gobster, P.H., and Delgado, A. (1993). 'Ethinicity and recreation use in Chicago's Lincoln park: In park user survey findings', USDA Forest Service General Technical Report, NE: 163, 75-81.

Green, R. (1999). 'Meaning and form in community perception of town character', Journal of Environmental Psychology, 19, 311-329.

Halpern, D. (1995). Mental health and the built environment: More than bricks and mortar?, London, Taylor and Francis.

Hammitt, W.E., Backlund, E.A. and Bixler, R.D. (2004). 'Experience use history, place bonding and resource substitution of trout anglers during recreation engagements', Journal of Leisure Research, 36:3, 356-378.

Handa, P. Barling, P. and Morrissy, E. (1981). 'Developments of perceived and preferred measures of physical and social characteristics of the residential environment their relationship and satisfaction', Journal of Community Psychology, 9, 118-124.

Harmon, D. (2006). 'People, Places, and Parks: Proceedings of the 2005 George Wright Society', Conference on Parks, Protected Areas, and Cultural Sites, Hancock, Michigan, USA. 
Hashas, M. (2003). 'Residents' Attachment to New Urbanist Versus Conventional Suburban Developments', PhD dissertation in community and Environmental design, North Carolina State University.

Hidalgo, M.C. and Hernandez, B. (2001). Place attachment: Conceptual and empirical questions, Journal of environmental Psychology, 21, 273-281.

Hummon, D. (1990). Commonplaces: Community Ideology and Identity in American Culture, State University of New York, Plenum.

Jacobs, M. (1995). Sustainability and community: Environment, economic rationalism and sense of place, Australian Planner, 32(2), 109-115.

Kaplan, S. and Kaplan, R. (1982). Humanscape: Environments for people, Ann Arbor, Ulrich's Books.

Keller, S. (1968). The urban neighborhood: Random house, New York.

Korpela, K. and Hartig, T. (1996). 'Restorative qualities of favorite places', Journal of Environmental Psychology, 16, 22-223.

Kyle, G.T., Absher, J.D. and Graefe, A.R. (2003). 'The moderating role of place attachment on the relationship between attitude toward fees and spending preference', Leisure Sciences, 25, 33-50.

Kyle, G., Graefe, A., Manning, R. and Bacon, J. (2004). 'Effects of place attachment on users' perceptions of social and environmental conditions in a natural setting', Journal of Environmental Psychology, 24, 213-225.

Lansing, J.B., Marans, R.W. and Zehner, R.B. (1970). Planned residential Environments,
Ann Arbor, University of Michigan, Survey Research Center.

Lawrence, D. (1992). 'Trancedence of Place', In I. Altman and S. Low (Eds.), Place attachment, New York, Plenum Press.

Lokaitou-Sideris, A. and Banerjee, T. (1998). Urban Design Downtown: Poetics and Politics of Form, University of California Press.

Low, S.M. and Altman, I. (Eds), Place Attachment, New York, Plenium Press.

Low, S.M., and Altman, I. (1992). 'Place attachment: a conceptual inquiry', In Low, S.M. and Altman, I. (Eds.) Place Attachment, New York, Plenum Press, 12, 1-12.

Low, S.M. and McDonogh, G.W. (2001). Remapping the city: Place, Order and Ideology, American Anthropologist, 103:1, 5-6.

Marcus, C.C. and Sarkissian, W. (1986). Housing as if People Mattered, Berkeley, University of California Press.

Marcus, C.C. (1992). 'Environmental memories', In low, S.M. and Altman, I. (Eds.) Place Attachment, New York, Plenum Press.

Marris, P. (1996). The politics of uncertainty: attachment in private and public life, New York, Routledge.

Mazmudar, S. (1993). 'Sacred Place and Place Attachment', Journal of Environmental Psychology, 13:3, 231-242.

Mesch, G.S. and Manor, O. (1998). 'Social ties, environmental perception, and local attachment', Environment and Behavior 30:4, 504-519. 
Milligan, M.J. (1998). 'Interactional past and potential: The social construction of place atttachment', Symbolic Interaction, 21:1, 1-33.

Moore, R.L. and Graefe, A.R. (1994). 'Attachments to reaction settings: The case of rail-trail users', Leisure Sciences, 16, 1731.

Newell, P.B. (1997). 'A cross-cultural examination of favorite places, environment and behavior, 29:4.

Oswald, F. and Wahl, H.W. (2001), Housing in old age: conceptual remarks and empirical data on place attachment, IAPS Bulletin of People-Environment Studies, N0.19, 7-11.
Prentice, D.A., and Miller D.T. (1992). 'When small effects are impressive' Psychological Bulletin, 112:1, 160-164.

Pretty, G., Chipuer, H.M., and Bramston, P. (2003). 'Sense of place among adolescence and adults in two rural Australian towns: The discriminating features of place attachment, sense of community and place dependence in relation to place identity', Journal of Environmental Psychology, 23, 273-287.

Proshansky, H.M., Fabian, A.K. and Kaminoff, R. (1983). 'Place-identity: physical world socialization of the self', Journal of Environmental Psychology, 3, 5783.

Proshansky, H.M. (1978). 'The City and Self-identity', Environment and Behavior, 10:2, 147-169.

How to cite this article: Amin Bahramian, Siamak Panahi, Jafar Yousefpour, Farzad Zarbakhsh, Defining Elements and Causes of Creating a Sense of Attachment and Belonging to Place by Studying the Interaction between Humans and the Artificial Environment. International Journal of Advanced Studies in Humanities and Social Science, 2019, 8(1), 45-60. http://www.ijashssjournal.com/article 84108.html 